Научная статья

УДК $81-25$

DOI: $10.18101 / 2686-7095-2021-1-12-20$

\title{
ФОРМЫ ДАВАЙ/ДАВАЙТЕ В РУССКОЙ УСТНОЙ СПОНТАННОЙ РЕЧИ («КОНТЕКСТЫ СОГЛАСИЯ»)
}

\author{
(C) Турчаненко Виктория Андреевна \\ учитель русского языка и литературы, \\ ГБОУ «СОШ № 580» г. Санкт-Петербурга \\ Россия, 197373, г. Санкт-Петербург, пр. Авиаконструкторов, 29, корп. 3 \\ e-viktoriya.turchanenko@gmail.com
}

\begin{abstract}
Аннотация. В статье описываются особенности функционирования глагольных форм давай/давайте в русской устной спонтанной речи. В естественной коммуникации эти формы часто «отрываются» от исходной глагольной парадигмы, проходят процесс грамматикализации и отчасти ресемантизации и обретают статус частиц или междометий. Конкретным предметом описания стали некодифицированные употребления исследуемых форм давай/давайте в роли «контекстов согласия»: давай в семь? \# давай в семь. Исследование проведено на материале корпуса повседневной русской речи «Один речевой день», описаны структурные особенности исследуемых единиц и их корреляции с социальными характеристиками говорящих.
\end{abstract}

Ключевые слова: устная речь; коллоквиалистика; корпусная лингвистика; звуковой корпус; грамматикализация; формула согласия.

\section{Для цитирования}

Турчаненко В. А. Формы давай/давайте в русской устной спонтанной речи («контексты согласия») // Вестник Бурятского государственного университета. Филология. 2021. Вып. 1. С. 12-20.

Устная речь обладает своими специфическими особенностями, которые отличают ее от письменной. Еще Л. В. Щерба писал, что «нужно прежде всего различать... два языка: один слышимый и произносимый, а другой написанный, которые находятся один к другому в известных отношениях, но не тождественны элементы одного не совпадают с элементами другого» [23, с. 11-12]. С этим мнением согласен и А. Мартине: «...речь и язык обладают независимыми организациями, в связи с чем можно... предположить существование лингвистики речи (здесь и далее курсив мой. - B. T.) наряду с лингвистикой языка» $[15$, с. 389].

Письменная речь обычно считается более приоритетной и престижной (в силу таких факторов, как зафиксированность в словарях и грамматиках, удобство для изучения, даже отчасти сакральность), однако она является, безусловно, вторичной формой существования языка, поскольку появилась гораздо позднее, чем устная разновидность языка, ср.: «несмотря на очевидную первичность устной речи, сложилась очень стойкая традиция, в силу которой устная речь воспринимается на фоне письменной речи и в параметрах этой последней» [12, с. 63].

Современная методика обработки данных с помощью компьютерных технологий позволяет анализировать материал, представленный в виде языковых и/или речевых корпусов. Нет сомнения, что в таких корпусах устная речь представлена наиболее репрезентативно. Кроме того, обращение к корпусным данным, как 
B. А. Турчаненко. Формы давай/давайте в русской устной спонтанной речи («контексты согласия»)

справедливо заметил В. А. Плунгян, позволяет «получать ответы на самые неожиданные вопросы - более того... ставить новые проблемы, которых лингвистика прошлого почти не касалась», и даже «отчасти заглянуть в будущее русского языка» $[17$, с. 13]. Именно потому предлагаемое исследование проведено на корпусном материале. Источником материала для него послужил корпус повседневной русской речи «Один речевой день» (ОРД), созданный петербургскими исследователями $[20 ; 7 ; 8 ; 9 ; 25 ; 26])$.

Объектом внимания в настоящей статье являются формы давай/давайте, часто выступающие в нашей устной речи в не зафиксированной словарями функции маркера согласия. Эти формы, как и многие другие единицы устной речи, подвергаются в ходе своего функционирования в устном дискурсе различным процессам ${ }^{1}$. Одним из таких процессов является грамматикализация, в результате которой языковая единица может изменить свое грамматическое значение, утратив часть морфологических признаков (или даже все признаки), вплоть до изменения части речи, ср.: сказать (глагол с полной парадигмой грамматических форм) $\rightarrow$ скажем (вводное слово со значением 'например, допустим' в «застывшей» форме 1 л. мн. ч., утратившее всякую грамматическую изменяемость); общий (имя прилагательное, способное изменяться по числам, родам и падежам) $\rightarrow$ в общем (неизменяемое наречие со значением 'в конечном результате, в итоге') и т. п.

Похожая судьба в устной речи наблюдается и у форм давай/давайте: глагольная форма со значением 'вручать кому что-либо; передавать из рук в руки' или 'предоставлять в чье-либо пользование; уделять; снабжать чем-либо' [3] становится формообразующей частицей, участвующей в создании аналитических форм повелительного наклонения со значением 'приглашения к совместному действию; предложения своих услуг, помощи' (давайте посидим, давай мириться) [3; 16, с. 360-361]. Надо отметить, что словари относят формы с такой частицей (1) к разговорным, так же как еще один вариант употребления давай в функции частицы (2): в сочетаниях с неопределенной формой глагола несов. вида она употребляется для выражения энергичного действия, в значении 'начал, стал, принялся' (схватил... и давай бежать) [16, с. 360-361]. Как просторечное употребление форм давай/давайте словари отмечают и еще одну частицу (3): она употребляется как понуждение к действию (Давай! Пей давай; давайте по домам) [16, с. 360-361].

Часто процесс грамматикализации глагола давать сопровождается параллельным процессом ресемантизации: форма «закрепляется» в языке как нечто «самостоятельное» и уже употребляется отдельно от полной побудительной формы глагола, ср.:

-

\footnotetext{
${ }^{1}$ Подробнее об актуальных процессах современной русской речи (грамматикализация, прагматикализация, редукция, самокоррекция, де- и ресемантизация и некот. др.) см., например: [7; 24].

2 Знак (\#) в транскриптах (расшифровках) ОРД означает мену говорящих, а в атрибуции к таким примерам дополнительно к характеристике говорящего (информанта: И1, И2, ...) указывается номер его собеседника (коммуниканта): женщины (Ж1, Ж2, ..), мужчины $(\mathrm{M} 1, \mathrm{M} 2, \ldots)$ или ребенка $(\mathrm{P} 1, \mathrm{P} 2, \ldots)$. Подробнее об особенностях орфографического
} 
Из самых последних изменений в употреблении форм давай/давайте можно отметить возможность для них использоваться как формулы прощзания (см. об этом: [21, с. 410-411; 13, с. 307; 22],) или согласия, ср.:

- $\quad$ да / *П давай до завтра тогда (И72) [прощание];

- $\quad$ хочешь со мной футбол смотреть ? \# буду / а кто сегодня играет ? давай (Р1 \# И70) [согласие].

Важно отметить также, что и исходные, и грамматикализованные формы $\partial a$ вай/давайте сосуществуют в нашей речи, что можно рассматривать как живой пример «следствия усложнения мысли» $[18$, с. 60].

В нашей статье описывается функционирование грамматикализованных форм давай/давайте в функции маркера согласия. Анализ корпусного материала осуществлялся в несколько этапов. На начальном этапе из корпуса ОРД были извлечены все контексты с единицами давай/давайте, независимо от особенностей их употребления. Так был сформирован первый пользовательский подкорпус, с которым работа была продолжена дальше. Этот корпус содержит в себе 1110 единиц давай/давайте в различных контекстах. Далее была дана количественная характеристика этого подкорпуса и на его основе сформирован второй, содержащий формы давай/давайте только в не зафиксированном словарями значении согласия (84 единицы, $8 \%$ всех употреблений).

Обращение к академическим словарям показало, что отдельно формы $\partial a$ вай/давайте как таковые встречаются в словарях редко, обычно можно увидеть отсылки к другим словарным статьям на глаголы дать и давать. Иногда упоминаются отдельные частицы давай/давайте, однако глагол со значением действия всегда находится на первом месте.

Наиболее полное толкование глагола давать приведено в «Словаре современного русского литературного языка» [3], где давай/давайте рассматриваются как формы повелительного наклонения. Лексические значения глагола давать описаны здесь довольно подробно, представим некоторые из них:

1) форма повелительного наклонения от глагола давать;

2) в сочетаниях с неопределенной формой глагола или с формой 1 л. мн. ч. буд. вр. употребляется как приглашение к совместному действию (давайте посидим вместе);

3) в просторечии выражает понуждение к действию (- Давай! - Григорий легонько подтолкнул Родиона в спину, и тот вихрем сорвался с места);

4) входит в состав фразеологизмов (как пить дать, даваться/даться в руки, не даться/не даваться в обиду, диву даваться и т. Д.).

Несмотря на такое обилие значений, среди них нет упоминания о возможности для форм давай/давайте выступать в роли согласия.

В «Словаре русского языка» [16, с. 360-361] видим похожую ситуацию: все возможные употребления сводятся к глаголу дать. Давай/давайте здесь являются либо формами повелительного наклонения глагола дать, имеющими значение приглашения к совместному действию или принуждения, либо выражением удивления, восхищения (нудаёшь!).

представления материалов ОРД см.: [20, с. 242-243]. 
B. А. Турчаненко. Формы давай/давайте в русской устной спонтанной речи («контексты согласия»)

В «Большом толковом словаре русского языка» под ред. С. А. Кузнецова [10, с. 237] есть словарная статья именно на единицу давай, однако авторы дают отсылку к другой словарной статье - на глагол давать, в которой приводятся те же значения, что были описаны выше в БАС, но менее подробно.

То же и в «Большом универсальном словаре русского языка» под редакцией В. В. Морковкина [11, с. 221-222], что несколько удивительно: если словари, указанные выше, были составлены довольно давно и, безусловно, нуждаются в доработке в связи с расширением лексических значений многих единиц языка ${ }^{1}$, то БУС - словарь относительно новый, но и там нет интересующего нас значения у форм давай/давайте. Нет упоминания об этом и в «Толковом словаре русской разговорной речи» $[21$, с. $410-411]$.

Упоминание о том, что давай/давайте может использоваться как выражение согласия, удалось найти только в небольшом примечании в «Русской грамматике»: «В качестве реплик в диалоге функционируют и многие другие из рассмотренных ... частиц, выражающие непосредственную реакцию на слова собеседника: — Пойдем? - Что ж. Давай (согласие)» [19, с. 728].

Из обзора данных словарей и грамматик можно заключить, что, во-первых, формы давай/давайте как формулы согласия присущи именно устной речи. Вовторых, они возникли, по всей видимости, относительно недавно и еще не успели попасть в словари (и не только академические), хотя фиксировались в текстах художественной литературы или в хрестоматиях русской разговорной речи, то есть в реальном употреблении.

В отличие от «контекстов прощания» [22], формы давай/давайте как выражение согласия обладают меньшей «самостоятельностью» и ближе находятся к первой степени «отрыва» от форм повелительного наклонения глагола, если говорить о своеобразной шкале грамматикализаиии ${ }^{2}$, которой в принципе, как уже отмечалось выше, подвергаются в устной речи формы давай/давайте. Этим, возможно, объясняется их более низкая встречаемость в материале исследования.

В каждом употреблении форм давай/давайте в «контексте согласия» можно наблюдать явление эллипсиса - пропуска какого-то элемента высказывания, который легко можно восстановить по контексту, и чаще всего пропускается глагол со значением побуждения к действию, чем и можно объяснить, по-видимому, от-

${ }^{1} \mathrm{O}$ стремлении современной лексикографии к «обновлению словарного пространства» $[5$, с. 7] лингвисты писали уже не раз, отмечая, что «жизнь слова в его реальном употреблении не всегда отражается и фиксируется словарями» [5, с. 7-8; см. об этом также: 6], что существует известная «несогласованность дефиниции того или иного слова и его реального употребления в речи рядового носителя языка» [4, с. 65]. См. также и более ранние работы об этом: Л. А. Капанадзе, Э. В. Столяровой, Н. А. Прокуровской и др. В связи с этим формулируются даже новые задачи, которые встают перед лексикографией и лексикографами, ср.: «задача лексикографа, если он не хочет покинуть почвы своей науки и превратиться в энциклопедиста, состоит в том, чтобы вскрыть наивную картину мира в лексических значениях и отразить ее в системе толкований» [1, с. 58].

${ }^{2} \mathrm{Cp}$.: «В последнее время вновь становится популярной мысль о том, что целесообразно отказаться от "прокрустова ложа" четкой и бескомпромиссной схемы и предпочесть метод количественной оценки, согласно которому каждое языковое явление должно описываться по месту, занимаемому им на шкале постепенных переходов (курсив мой. - В. T.)» $[2$, c. 89$]$. 
сутствие в словарях специального значения согласия для рассматриваемых форм. Ср. (в квадратных скобках в примерах восстановлены пропущенные элементы высказывания):

- а (э) кухня это (?) молодёжь // \# у меня телефон / я возьму сейчас // \# давай [возьми] / ага (И146 \# Ж1 \# И146);

- пошли ставить батарею // \# не-не-не / ты (э) где-то через часик / *П полтора // \# ну давай [пойдем ставить батарею где-то через часик] / во сколько ? (M3 \# И124 \# М3);

- может ему подвернуть чуть? *П \# давай [подвернем] (Ж1 \# И124).

На материале ОРД видно, что формы давай/давайте находятся в контекстах в непосредственной близости с теми частицами и междометиями, которые также выражают согласие: да, ага, всё, угу, хорошо, ну, ладно, конечно, можно (в контекстах ниже подчеркнуты). Таким образом, все эти единицы встают в один синонимический ряд и становятся отчасти взаимозаменяемыми, ср.:

- твоя ж совесть человека крепкая / ну говорю / ладно давай (И115);

- фотки ещё посмотришь сейчас / я всем перед прошльм // \# хорошо / давай (И111 \# М1);

- лучше левую часть давайте посмотреть // \# ну давай // \# там он так же / только симметрично просто / вот он (И110 \# Ж1 \# И1 10);

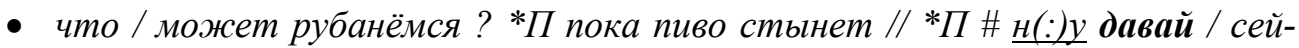
час / с(:)екунду (И100 \# М1);

- вот так надо мусор убрать этот // *П \# ну можно да / давай (И91 \# Ж3);

- купаться чего поедем не ? на какой новый ? а да поехали $\underline{\partial a} / / \underline{\partial a}$ давай (И84);

- ага / пойдём / пойдём выйдем // \# угу / давай (И78 \# Ж1);

- по идее / они должны заехать завтра рано утром / да / *H / в твою смену //@yгу// *П они на Фонтанку\$ // *П а / на Фонтанку\$ // \# и на не переспросила адрес! *П я сказала / ой / есть только номер на Фонтанке\$! *П $\underline{\text { да / хоро- }}$ шо / давайте (Ж1@ И77);

- а просто я думал / я же забыл про него / давай / конечно / чего там // \# ой / * $\mathrm{H} / \mathrm{mbl}$ *Н не забыл (И102 \# Ж1).

В 24 случаях из 84 (29\%) формы давай/давайте как выражение согласия появляются в условиях вопросно-ответной коммуникации, когда из реплик говорящих образуется пара: стимулом к согласию становится высказывание с побуждением к действию или каким-то предложением, реакцией на стимул - утвердительный ответ с формами давай/давайте:

- так я кофе ставлю ? *П \# ну давай (И131 \# Ж1);

- может ему подвернуть чуть ? *П \# давай (Ж1 \# И124);

- хотите красный (...) апельсинчик ? *П \# давай(?) (И109 \# Ж1).

Думается, что с учетом этой особенности (служить ответной репликой на какой-то стимул собеседника) «контексты согласия» давай/давайте можно причислить к классу дискурсивных формул русской устной речи, представляющих собой «устойчивые, легко воспроизводимые изолированные конструкции», которые служат «ответными репликами в диалоге (курсив мой. - B. T.) и, в отличие от традиционных конструкций, не содержат переменных внутри себя» [14, с. 143]. 
B. А. Турчаненко. Формы давай/давайте в русской устной спонтанной речи («контексты согласия»)

Анализ материала второго пользовательского подкорпуса показал также, что в реакции собеседника может срабатывать повторение сценария, условно: давай? $\rightarrow$ давай. Это явление можно наблюдать, например, в следующих контекстах (они составляют 20 \% от общего количества материала в данном подкорпусе):

- давай в семь ? *П \# давай в семь (И132 \# Ж1);

- давай сегодня вместе сделаем открытку ?@давай //@но это будет как подарокот тебя / яммаме подарюкнижку (P1@И129@ (1);

- ну давай её ... давай её жёлтеньким выделю ! \# ну давай жёлтеньким (Ж1 \# И72).

Отметим также, что в семи контекстах (8\%) в реакции повторяется слово или выражение, изначально содержавшиеся в стимуле (в контекстах подчеркнуты):

- давай в семь ? *П \# давай в семь (И132 \# Ж1);

- мне вот / вот / вот этот // \# давай этот (Ж1 \# И177);

- давай я тебе одну книжку подарю ? \# давай / подари мне пожалуйста одну книжку (P \# M1);

- Светлана_Николаевна\% / это вот это ж прошлый век / вот смотрите // \# на бе.. бе.. бе.. бе... на беленьком // \# давайте на беленьком (И109 \# Ж1 \# И109).

Отдельно стоит выделить группу контекстов (16 ед.), в которых согласие выражается конструкцией <формообразующая частица давай/давайте + глагол>, что является реализацией словарных значений исследуемой единицы. Причиной выделения таких контекстов в отдельную группу является «перетягивание» выражения согласия непосредственно на формы давай/давайте, которые можно заменить утвердительной частицей $\partial a$. Но поскольку в данных контекстах представлена вполне стандартная словарная формула частица + глагол, они не были включены во второй пользовательский подкорпус для анализа:

- давай всё достанем потому что я ж на низ-то камни буду класть // *П \# ну давай достанем (Ж1 \# И91);

- возьмёшь персики(?)? *П \# давай возьму (Р1 \# И113);

- на вторую тоже сделаем? *П \# давай сделай (И113 \# Ж1);

- а я просто позвоню тогда Татьяне\% и... и уточню // \# давайте / уточниme / да (И113 \# Ж1);

- Наталья_Борисовна\% / ещзё насчёт семинара / *B (э-э) ф)(:) я вот так подумал / (...) (э-э) или Катю\% перенести / (...) может быть вообще её так сказать ближе туда к делу / понимаете ? потому что *B (э-э) я хочу / чтобы её как бы предз... ну вот выступление было как реально предзашита / а не просто вот что-то такое /@давайте перенесём / *H конечно / *Hнет (И127@ Ж2).

Для социолингвистического исследования материала пользовательского подкорпуса полностью и достоверно доступна информация только о поле говорящих (как информантов, так и их коммуникантов). Проведенный анализ показал следующее.

58 единиц в «контекстах согласия» (69\%) были употреблены женщинами, и только 26 (31\%), в два раза меньше, - мужчинами. Из 15 информантовженщин пять человек употребили согласие давай/давайте больше, чем один раз - от 2 до 4. Из 12 информантов-мужчин только у троих формы да- 
вай/давайте как согласие были употреблены больше, чем один раз — по два раза на каждого.

Если говорить о возрасте и роде деятельности информантов, то здесь наблюдается большое разнообразие. Была проанализирована речь информантов от 24 до 83 лет, без особых отличий в какой-либо возрастной группе. Разнообразен также и род деятельности говорящих: менеджмент, бухгалтерский учет, инженерная и сантехническая сферы, IT-сфера, анализировалась также речь неработающих пенсионеров и научных сотрудников.

Меньшая частотность давай/давайте как «контекстов согласия» (по сравнению с «контекстами прощания»), вероятно, связана с еще не до конца оформленной «независимостью» данных форм от их словарного значения. Согласие с использованием форм давай/давайте часто возникает как реакция на стимул собеседника, выраженный вопросом или предложением/побуждением; нередко возникает повторение сценария, в котором и стимул, и реакция содержат формы $\partial a-$ вай/давайте. Так же как и в случае с этикетными формулами прощания, согласие давай/давайте встречается в речи людей любого возраста, пола и профессии.

Думается, однако, что полученные данные могут быть полезны в различных теоретических и прикладных аспектах лингвистики; в частности, в лексикографической, преподавательской и переводческой практике.

\section{Литература}

1. Апресян Ю. Д. Избранные труды. Т. І: Лексическая семантика. 2-е изд., испр. и доп. Москва: Школа «Языки русской культуры», Восточная литература РАН, 1995. 472 с. Текст: непосредственный.

2. Арутюнова Н. Д. О критерии выделения аналитических форм // Аналитические конструкции в языках различных типов / редакторы В. М. Жирмунский, О. П. Суник. Москва; Ленинград: Наука, 1965. С. 89-93. Текст: непосредственный.

3. Словарь современного русского литературного языка: в 17 т. Т. 3: Г-Е / Редакционная коллегия С. Г. Борхударов, В. В. Виноградов [и др.]. Москва; Ленинград: АН СССР, 1954. С. 517-528. Текст: непосредственный.

4. Богданова Л. И. Когнитивная информация для толковых словарей // Вестник МГУ. Cер. 19: Лингвистика и межкультурная коммуникация. 2012. № 2. С. 65-70. Текст: непосредственный.

5. Богданова Л. И. Слово в речи и в словаре // Слово и словарь $=$ Vocabulum et vocabularium: сборник научных материалов / главный редактор И. Л. Копылов. Минск: Четыре четверти. 2017. С. 7-12. Текст: непосредственный.

6. Богданова Н. В. Русское слово в трех режимах фиксации - словарь, ментальный лексикон и реальное употребление (лексикографический и лингвометодический аспекты) // Русский язык за рубежом. 2011. № 6. С. 6-14. Текст: непосредственный.

7. Богданова-Бегларян Н. В. Устная спонтанная речь и разнообразие происходящих в ней процессов // Cross Cultural Studies: Education and Science (CCS\&ES). - Iss. III, November 2016. С. 26-31. Текст: непосредственный.

8. Корпус «Один речевой день» в исследованиях социолингвистической вариативности русской разговорной речи / Н. В. Богданова-Бегларян, Т. Ю. Шерстинова, О. В. Блинова, Г. Я. Мартыненко // Анализ разговорной русской речи (AP3-2017): труды 7-го междисципл. семинара / науч. ред. Д. А. Кочаров, П. А. Скрелин. Санкт-Петербург: Политехника-принт, 2017. С. 14-20. Текст: непосредственный.

9. Корпус русского языка повседневного общения «Один речевой день»: текущее состояние и перспективы / Н. В. Богданова-Бегларян, О. В. Блинова, Г. Я. Мартыненко, 
B. А. Турчаненко. Формы давай/давайте в русской устной спонтанной речи («контексты согласия»)

Т. Ю. Шерстинова // Труды Института русского языка им. В. В. Виноградова. Вып. 21: Национальный корпус русского языка: исследования и разработки / гл. ред. А. М. Молдован; отв. ред. вып. В. А. Плунгян. Москва: ИРЯ РАН, 2019. С. 100-109. Текст: непосредственный.

10. Большой толковый словарь русского языка / гл. ред. С. А. Кузнецов. СанктПетербург: Норинт, 2000. 1536 с. Текст: непосредственный.

11. Большой универсальный словарь русского языка / под ред. В. В. Морковкина. Москва: Словари XXI века; Аст-Пресс Школа, 2016. 1456 с. Текст: непосредственный.

12. Гаспаров Б. М. Устная речь как семиотический объект // Семантика номинации и семиотика устной речи: уч. зап. Тартус. гос. ун-та. Вып. 442: Лингвистическая семантика и семиотика I / отв. ред. М. А. Шелякин. Тарту: Тартус. гос. ун-т, 1978. С. 63-112. Текст: непосредственный.

13. Ермолова О. Б., Богданова-Бегларян Н. В. Языковое оформление прощания в современной разговорной речи (на материале звукового корпуса «Один речевой день») // Коммуникативные исследования. 2019. Т. 6, № 2. С. 307-331. Текст: непосредственный.

14. Жукова С. Ю., Орехов Б. В., Рахилина Е. В. Дискурсивные формулы русского языка: диахронический подход // Труды Института русского языка им. В. В. Виноградова. Вып. 21: Национальный корпус русского языка: исследования и разработки / гл. ред. А. М. Молдован; отв. ред. выпуска В. А. Плунгян. М.: ИРЯ РАН, 2019. С. 140-163. Текст: непосредственный.

15. Мартине А. Основы общей лингвистики // Новое в лингвистике. Вып. 3 / сост., ред. и вступ. ст. В. А. Звегинцева. Москва : Изд-во иностр. лит., 1963. С. 366-566. Текст: непосредственный.

16. Словарь русского языка: в 4 т. 4-е изд., стер. Т. 1: А-Й / под редакцией А. П. Евгеньевой. Москва: Русский язык; Полиграфресурсы, 1999. 702 с. Текст: непосредственный.

17. Плунгян В. А. Зачем нужен Национальный корпус русского языка? Неформальное введение // Национальный корпус русского языка: 2003-2005. Москва: Индрик, 2005. С. 6-20. Текст: непосредственный.

18. Потебня А. А. Из записок по русской грамматике. Т. 1-2. Москва: Учпедгиз, 1958. 536 с. Текст: непосредственный.

19. Русская грамматика: в 2 т. Т. 1: Фонетика. Фонология. Ударение. Интонация. Словообразование. Морфология / главный редактор Н. Ю. Шведова. Москва: Наука, 1980. 783 с. Текст: непосредственный.

20. Русский язык повседневного общения: особенности функционирования в разных социальных группах: коллект. монография / ответственный редактор Н. В. БогдановаБегларян. Санкт-Петербург: ЛАЙКА, 2016. 244 с. Текст: непосредственный.

21. Толковый словарь русской разговорной речи. Вып. 1: А-И / под редакцией Л. П. Крысина. Москва: ЯСК, 2014. 776 с. Текст: непосредственный.

22. Турчаненко В. А. Формы ДАВАЙ/ДАВАЙТЕ в русской устной спонтанной речи («контексты прощания») // Социо- и психолингвистические исследования. 2020.№ 8. С. 48-55. Текст: непосредственный.

23. Щерба Л. В. О служебном и самостоятельном значении грамматики как учебного предмета // Щерба Л. В. Избранные работы по русскому языку. Москва: Учпедгиз, 1957. С. 11-20. Текст: непосредственный.

24. Bogdanova-Beglarian, N., Filyasova, Yu. Active Processes in Modern Spoken Language (Evidence from Russian) // Digital Transformation and Global Society. Third International Conference, Conference proceedings DTGS 2018, St. Petersburg, Russia, May 30 - June 2, 2018, Revised Selected Papers, Part II. Communications in Computer and Information Science (CCIS). Vol. 859 / D. A. Alexandrov, A. V. Boukhanovsky, A. V. Chugunov, Yu. Kabanov, O. Koltsova (eds.). Springer, Cham. 2018. Рp. 391-403. Текст: непосредственный. 
25. An Exploratory Study on Sociolinguistic Variation of Spoken Russian / BogdanovaBeglarian, N., Sherstinova, T., Blinova, O., Martynenko, G. // SPECOM 2016. Lecture Notes in Artificial Intelligence, 2016a. Vol. 9811. P. 100-107.

26. Sociolinguistic Extension of the ORD Corpus of Russian Everyday Speech / BogdanovaBeglarian, N., Sherstinova, T., Blinova, O. [at al.] // SPECOM 2016. Lecture Notes in Artificial Intelligence, 2016b. Vol. 9811. P. 659-666.

Статья поступила в редакцию 24.11.2020; одобрена после рецензирования 28.01.2021; принята к публикации 25.03.2021.

\section{FORMS OF 'DAVAY/DAVAYTE’ IN RUSSIAN SPONTANEOUS SPEECH («CONTEXT OF CONSENT»)}

Viktoriya A. Turchanenko

Russian Language and Literature Teacher,

St Petersburg Secondary School No 580

29, 3a, Aviakonstruktorov Ave., St Petersburg 197373, Russia

viktoriya.turchanenko@gmail.com

Abstract. The article reviews the functioning of the verb forms 'davay/davayte' in Russian oral spontaneous speech. In natural communication, these forms often "break away" from the original verbal paradigm, go through the process of grammaticalization and partly resemantization, and acquire the status of particles or interjections. The specific subject of description is the uncodified use of the studied forms of davay/davayte in the role of "consent contexts": davay v sem'? \# davay v sem'. The article based on the material of the corpus of everyday Russian speech "One speaker's day" describes the structural features of the studied units and their correlation with the social characteristics of speakers.

Keywords: oral speech; colloquialism; corpus linguistics; speech corpus; grammaticalization; consent formula.

For citation

Turchanenko V. A. Forms 'davay/davayte' in Russian Spontaneous Speech ("context of consent”). Bulletin of Buryat State University. Philology. 2021; 1: 12-20 (In Russ.).

The article was submitted 24.11.2020; approved after reviewing 28.01.2021; accepted for publication 25.03.2021. 